\title{
Nasal Spray, Suspension Dosage Form
}

National Cancer Institute

\section{Source}

National Cancer Institute. Nasal Spray, Suspension Dosage Form. NCI Thesaurus. Code C149689.

Liquid single-dose or multidose preparation consisting of a suspension in a container with or without a metering dose valve or in a container with a spray pump or equivalent device to create a spray, intended for nasal use. 